\title{
Relationship of Study Habit to Intelligence Quotient Level and Academic Performance
}

\author{
Elymar A. Pascual \\ elymarpascual@rocketmail.com \\ Department of Education, Nagcarlan, Laguna, Philippines, 4002
}

\begin{abstract}
Nothing is stronger than a habit. When a habit is already established in the system or routine of an individual, it promises great, or on the opposite, damaging result to the life of that individual. The purpose of this study is to find out the relationship of study habit and Intelligence Quotient Level of high school students. Sixty high school students of Sta. Cruz, Laguna, Philippines participated in this study. It was found out that the mean level of study habit of high school students is 2.57 (frequent), the mean IQ level is 107 (average), and the mean level of academic performance is 84.12 (average). Also, it was found out that the study habit of high school students has nothing to do with their IQ level; study habit and academic performance of high school students has a low to moderate relationship, and the IQ level of high school students significantly affects their academic performance. A more frequent parent-teacher conference will play a very vital role in making the plan to create consistency. This, of course will materialize if parents have realized that they have a big part/role on their children's achievement. Peers, parents and school should work together to improve students' performance.
\end{abstract}

Keywords: study habit; intelligence quotient; academic performance

\section{Introduction}

EDSOURCE on-line, a website in the internet, posted an article in June 1999 stating that California parents, educators and business leaders alike have been concerned about the lagging achievement of the states' students, high school students in particular. This concern has led, most notably, to the passage of a new state law requiring that, beginning in the year 2004, all California students pass a high school exit exam before receiving a diploma.

The United Evangelical Church School has the same dilemma as to why high school students' performance are low. Records show that grades of the students in high school are low. The school thought of how to address this problem because all advisory teachers and subject teachers believe that they (the students) have so much potentials, only they are not utilizing it.

About $85 \%$ of the parents of high school students' population are absentee parents, if not an OFW, single-parent or just plain "busy" parent/s. But the school know it very well what impact it would have to children, especially because the school advocates strong partnership of school and parents. Though off course it is not solely the factor that would affect the child's performance in school as what was included in the article EDSOURCE. And with the observation of the majority of the teachers that most of the students are carefree about their grades. They do not care much what grade would they get. A lot of test items are not answered, if not, with answers but not thought cautiously.

These only show how complex a study would be if one would conduct a research. So to be able to really help students improve their academic status, the researchers trimmed down the variables to study habit and intelligence quotient level. The school, through the Guidance Office decided to conduct a research to see the relationship of these two variables to the academic performance of the students. Through this study, relationship and significant effect of these variables to each other can be seen and concluded, and so, 
formulate methods that will result in meeting their needs and maximizing their potentials towards the 107 realization of the mission and vision of the school.

\subsection{Statement of the Problem}

The purpose of this study is to find out the relationship of study habit and Intelligence Quotient Level of high school students of United Evangelical Church School, Sta. Cruz, Laguna, s.y. 2006-2007.

Specifically, it sought to answer the ff. questions:

- What is the attitude of high school students in UEC School with regards to their study habit?

- What is the mean level of Intelligence Quotient of the high school students in UEC School?

- What is the mean level of academic performance of the high school students in UEC School?

- Is there a significant relationship in the attitude towards study habit and Intelligent Quotient Level of high school students at UEC School?

- Is there a significant relationship in the attitude towards study habit and academic performance of high school students at UEC School?

- Does intelligent quotient affect the academic performance of high school students at UEC School?

\subsection{Significance of the Study}

The following will be benefited through this study:

School Officials - Principals, administrators and guidance counselors are key persons who give direction to the school. Through this study, they can find insight on the needs of the students and the probable solution to these needs base on the result of the study.

Teachers - Teachers, especially the advisers and the would-be advisers of the students concerned in this study will have knowledge of the students' capacity and the means of helping and motivating them in their study.

Students - Students, through their adviser and the guidance counselor will know themselves well. Through the collaboration of school officials, teachers and parents, students' academic performance can improve once the conclusion and recommendation accompanying this study are realized.

Parents - Parents can find insight through this study about their important role in guiding their children towards better academic performance.

Readers and Researchers - Future readers and researchers can start with the basics presented in this paper and have a further investigation of the findings that result in this study.

\section{Review of Related Literature}

\subsection{Study Habit}

"Nothing is stronger than a habit", according to Ovid, a famous Roman poet. He is implying that when a habit is already established in the system or routine of an individual, it promises great, or on the opposite, damaging result to the life of that individual. In the context of education, Kirwan (2006) said,"Whether you're in middle school or graduate school, you'll find that lack of organization is the main cause of low academic performance. With multiple teachers to answer to and different class schedules and assignments to track, unorganized students find themselves quickly falling behind in their grade point average." "Lack of organization" in the statement of Kirwan is parallel to poor study habit which is one of the variables in this present study.

\subsection{Intelligence Quotient}

Intelligence quotient, or IQ, is a number used to indicate a person's intelligence. A person's IQ is based on a comparison of his or her score on an intelligence test with the scores of others on the same test. 
Sternberg (1986) in his article "Why Intelligent People Fail" believes that conventional intelligence 108 tests tell us little about performance in everyday life and suggest a number of reasons why so-called intelligent people fail:
a.) lack of motivation
b.) lack of impulse control
c.) lack of perseverance
d.) fear of failure
e.) procrastination
f.) inability to delay gratification
g.) too little/too much self-confidence

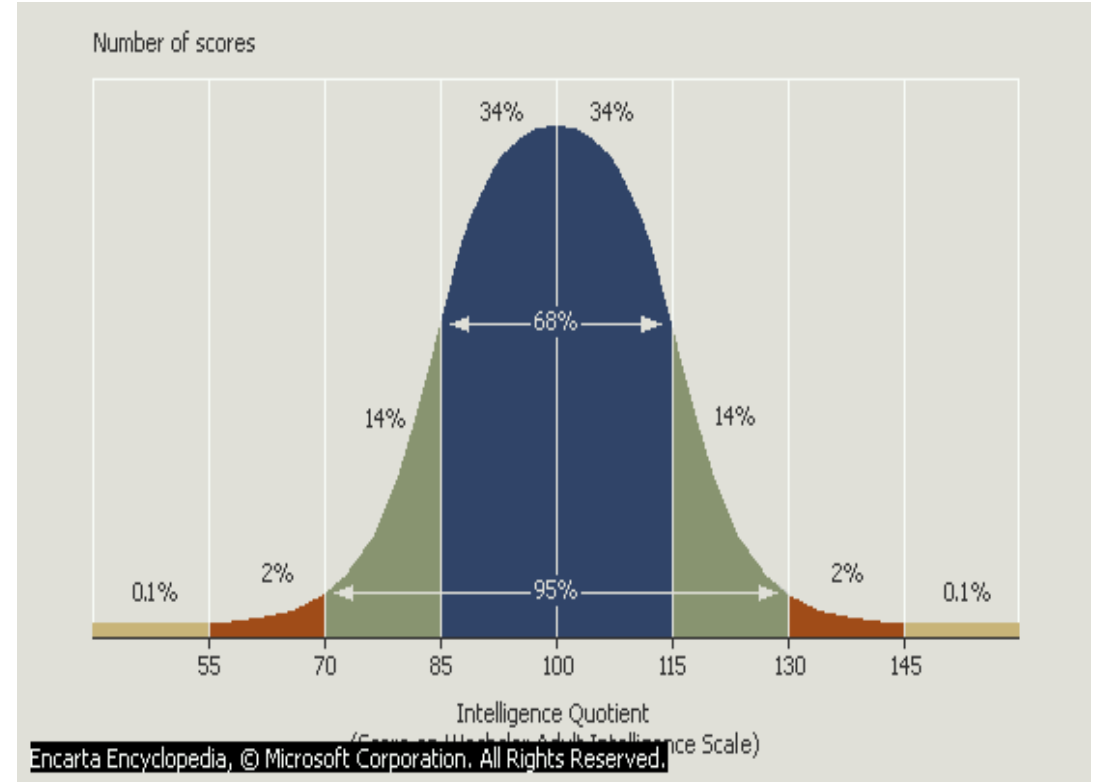

Figure 1. Distribution of IQ Scores

The distribution of intelligence quotient (IQ) scores on the Wechsler Adult Intelligence Scale follows a bell-shaped or normal curve, which is an average distribution of values. It shows that 95 per cent of people score between 70 and 130. This comprises the people under the below average up to above average in terms of intelligent quotient level.

These readings serve as foundation in determining the mean intelligence quotient level of the high school students in UEC School, and in understanding why students with high IQ level may still possibly have low academic performance.

\subsection{Academic performance}

Academic is more of theoretical interest rather than practical. On the other hand, performance deals about what is accomplished academically and it is contrasted with capability. Steinberg and Noguera, known scholars and researchers, shared their different and yet often complementary perspectives on the cultural, familial and institutional factors that have the most potent influence on student learning and academic performance at a recent Ed source conference. These are some factors that affect student academic performance:

a.) ethnic differences in attitudes towards school;

b.) influence of peers; 
c.) too many parents have "checked out";

d.) the dangerous lure of after school employment;

e.) failure is not seen; and

f.) differences in family background

In the list of Steinberg and Noguera, study habit and intelligence quotient level are not listed. This means that study habit and intelligence quotient level are not yet probed as possible factors affecting students' academic performance. Nevertheless, their study is related with the present one specially in formulating recommendation that will result out of the findings of this research.

\subsection{Hypotheses}

The tentative answers for the problem posed at the beginning of the study are the following:

1.) There is no significant relationship in the attitude towards study habit and Intelligent Quotient Level of high school students at UEC School.

2.) There is no significant relationship in the attitude towards study habit and academic performance of high school students at UEC School.

3.) Intelligent quotient does not affect the academic performance of high school students at UEC School.

$$
\text { Paradigm }
$$

IV

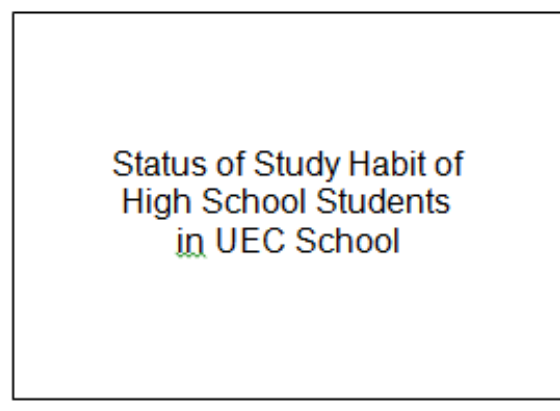

Frame 1
DV

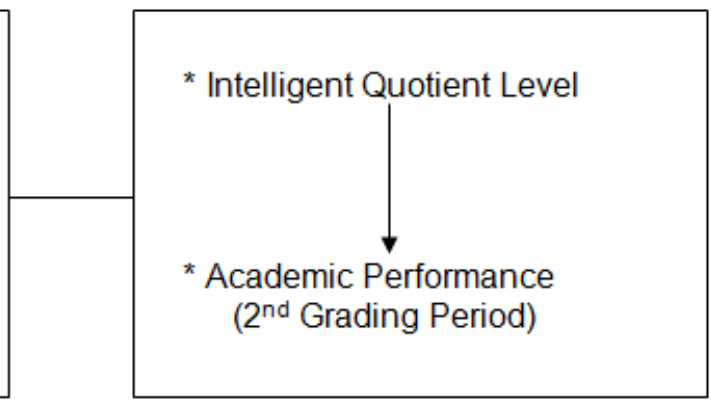

Frame 2

Frame 1 shows the independent variable, study habit of high school students in UEC School, while Frame 2 shows the dependent variables, Intelligent Quotient Level and Academic Performance. Frame 1 and Frame 2 is connected with a segment to show possible relationship between variables. Intelligent Quotient Level is connected to Academic Performance through an arrow to show possible effect of one variable to another.

\section{Research Design and Methodology}

This study made use of a standardized 50-item IQ Test 1.0, copyright 1991 by Terry Wilkins. This IQ Test is a multiple choice type of test which include Mathematics, Science, English and logical reasoning. It was administered to high school students in a period of 30 minutes. Basically, the IQ Level of a person falls on one of the following levels:

$$
\begin{array}{ll}
\text { U } & - \text { underdeveloped } \\
\text { BA } & - \text { Below Average } \\
\text { A } & - \text { Average } \\
\text { AA } & - \text { Above Average } \\
\text { G } & - \text { Gifted }
\end{array}
$$




$$
\begin{array}{ll}
\text { HG } & - \text { Highly Gifted } \\
\text { GE } & - \text { Genius } \\
\text { HGE } & - \text { High Genius } \\
\text { HiGE } & - \text { Highest Genius }
\end{array}
$$

Survey questionnaire to measure students' attitude towards study habit was validated by the principal, and the final survey questionnaire includes the following items:

- I have set for myself a specific and regular schedule for studying my lessons at home.

- I give more time in studying those subjects that I find difficulty with than those subjects that I'm at ease.

- I do advance readings of the topics in our subjects especially when the next topic is announced.

- I open my notebooks and books at home to review the lessons we have discussed that day even though there's no assignment.

- I allot more time in studying my lessons during weekdays than in doing other things like watching TV program or playing computer games.

- I also have time in studying my lessons even on weekends.

- I am ready to answer the questions of my teachers with regards to the lessons we have studied the previous meeting.

- I jot down requirements and assignments in school to remind me of the things that I must accomplished at home.

- I submit requirements and assignments on time.

- I do not sleep at night or go to school in the morning without studying my lessons.

- I study lessons at home even though examination time is still far.

- I'm already relaxed and does not experience pretest jitters on the day of the examination.

Students gave rate to themselves using the following scale:

5 - Highly characteristic of me

4 - Most of the time this would describe me

3 - Frequently characteristic of me

2 - Occasionally characteristic of me

1 - Not at all characteristic of me

Weighted mean was used to get the attitude of the students with regards to study habit, while simple mean was used to get the average IQ Level and academic performance of students. Pearson R fits the process of getting the relationship between study habit and IQ Level and between study habit and academic performance. On the other hand, the significant effect of IQ Level to academic performance is measured through t-test.

\section{Presentation, Interpretation and Analysis of Results}

This chapter presents in table form the data gathered. Interpretation accompanies every table, and analysis was added on the last table (table 5) which is the summary of the first four tables.

Table 1. First Year High School Students' Study Habit, IQ Level, Academic Performance, and their Relationships

\begin{tabular}{|l|r|r|}
\hline Mean of Study Habit & 2.84 & frequent \\
\hline Mean IQ Level & 104 & average \\
\hline Mean of Acad. Perform. & 83.68 & average \\
\hline r of Study Habit to IQ Level & -0.03 & none \\
\hline
\end{tabular}




\begin{tabular}{|l|r|rl|}
\hline $\begin{array}{l}\text { r of Study Habit to Acad. } \\
\text { Performance }\end{array}$ & 0.41 & low/mod. & \\
\hline t stat for IQLevel \& Acad.Per. & 8.42 & CV=2.02 & $\mathrm{S}$ \\
\hline
\end{tabular}

Table 1 shows the frequent (2.84) study habit of first year high school students, an average (104) IQ Level, and average (83.68) academic performance. As to study habit and IQ Level, there's no relationship ($0.03)$ existing. Study habit and academic performance shows a low to moderate (0.41) relationship. On the other hand, IQ Level significantly affects the academic performance of first year high school students as shown by greater t-value (8.42) than critical value (2.02).

Table 2. Second Year High School Students' Study Habit, IQ Level, Academic Performance, and their Relationships

\begin{tabular}{|l|r|c|}
\hline Mean of Study Habit & 2.51 & frequent \\
\hline Mean IQ Level & 112 & average \\
\hline Mean of Acad. Perform. & 84.03 & average \\
\hline $\begin{array}{l}\text { r of Study Habit to IQ Level } \\
\text { Performance }\end{array}$ & 0.09 & none \\
\hline \begin{tabular}{l} 
t stat for IQLevel \& Acad.Per. \\
\hline
\end{tabular} & 0.64 & moderate \\
\hline
\end{tabular}

Table 2 shows the frequent (2.51) study habit of second year high school students, an average (112) IQ Level, and average (84.03) academic performance. As to study habit and IQ Level, there's no relationship (0.09) existing. Study habit and academic performance shows a moderate (0.64) relationship. On the other hand, IQ Level significantly affects the academic performance of second year high school students as shown by greater t-value (7.85) than critical value $(2.06)$.

Table 3. Third Year High School Students' Study Habit, IQ Level, Academic Performance, and their Relationships

\begin{tabular}{|l|r|c|}
\hline Mean of Study Habit & 2.12 & occasional \\
\hline Mean IQ Level & 112 & average \\
\hline Mean of Acad. Perform. & 84.67 & average \\
\hline $\begin{array}{l}\text { r of Study Habit to IQ Level } \\
\text { r of Study Habit to Acad. }\end{array}$ & 0.41 & \multicolumn{1}{|c|}{ low } \\
\hline Performance & 0.46 & low/mod. \\
\hline t stat for IQLevel \& Acad.Per. & 7.34 & CV=2.06 S S \\
\hline
\end{tabular}

Table 3 shows the occasional (2.12) study habit of third year high school students, an average (112) IQ Level, and average (84.67) academic performance. As to study habit and IQ Level, there's a low (0.41) existing. Study habit and academic performance shows a low to moderate $(0.46)$ relationship. On the other hand, IQ Level significantly affects the academic performance of third year high school students as shown by greater t-value (7.34) than critical value (2.06). 
Table 4. Fourth Year High School Students' Study Habit, IQ Level, Academic Performance, and their 1150 Relationships

\begin{tabular}{|l|r|c|}
\hline Mean of Study Habit & 2.69 & frequent \\
\hline Mean IQ Level & 98 & average \\
\hline $\begin{array}{l}\text { Mean of Acad. Perform. } \\
\text { r of Study Habit to IQ Level }\end{array}$ & 84.50 & average \\
\hline $\begin{array}{l}\text { r of Study Habit to Acad. } \\
\text { Performance }\end{array}$ & 0.71 & high \\
\hline $\begin{array}{l}\text { t stat for IQLevel \& Acad.Per. } \\
\text { moderate }\end{array}$ & 2.15 & CV=2.14 S \\
\hline
\end{tabular}

Table 4 shows the frequent (2.69) study habit of fourth year high school students, an average (98) IQ Level, and average (84.50) academic performance. As to study habit and IQ Level, there's a high relationship (0.71) existing. Study habit and academic performance shows a moderate (0.63) relationship. On the other hand, IQ Level significantly affects the academic performance of fourth year high school students as shown by greater t-value (2.15) than critical value (2.14).

Table 5. Overall Study Habit, IQ Level, Academic Performance, and their Relationships

\begin{tabular}{|l|r|c|}
\hline Mean of Study Habit & 2.57 & frequent \\
\hline Mean IQ Level & 107 & average \\
\hline Mean of Acad. Perform. & 84.12 & average \\
\hline r of Study Habit to IQ Level & 0.05 & none \\
\hline $\begin{array}{l}\text { r of Study Habit to Acad. } \\
\text { Performance }\end{array}$ & 0.42 & low/mod. \\
\hline t stat for IQLevel \& Acad.Per. & 12.31 & $\mathrm{CV}=1.98 \quad \mathrm{~S}$ \\
\hline
\end{tabular}

Table 5 shows the frequent (2.57) study habit of high school students, an average (107) IQ Level, and average (84.12) academic performance. As to study habit and IQ Level, there's no relationship (0.05) existing. Study habit and academic performance shows a low to moderate $(0.412$ relationship. On the other hand, IQ Level significantly affects the academic performance of high school students as shown by greater $\mathrm{t}$ value (12.31) than critical value (1.98).

The none relationship of study habit and IQ Level is supported by the reason that study habit is connected with the attitude of the students, while IQ Level is intellectual in nature. The low to moderate relationship of study habit and academic performance implies that a good and established study habit of a student is evident in his good academic performance (Kirwan, 2006). While this is true, the IQ level of the student also has an added effect to his academic performance.

\section{Conclusions and Recommendation}

The following findings answer the specific questions posed at the beginning of this study:

- The high school students of UEC School has a frequent study habit;

- The mean IQ Level of high school students of UEC School is average.

- The mean level of academic performance of high school students of UEC School is average. 
- The study habit of high school students has nothing to do with their IQ Level.

- The study habit and academic performance of high school students has a low to moderate relationship.

- The IQ Level of high school students significantly affects their academic performance.

These imply that teachers should always encourage students to have a good study habit, if ever possible, teachers should make a way to check students' study habit on weekdays and even on weekends. Advisers should have an active role in doing this. Although this seems to be elementary in way, advisers can greatly help their students if they can devise a plan in encouraging students to make a specific plan so that students can devote ample time on every subject specially the major ones.

A suggested steps in building good study habit is presented here:

Four Steps to Success (Building a Study Habit.pdf)

1.) Choose a goal.

2.) See yourself succeeding.

3.) Choose a quality that will help you reach your goal.

4.) Create a new habit that will help you reach your goal. Here's how:

a.) Identify a situation that will help you practice your goal.

b.) Describe when, where, and with whom this situation happens.

c.) Describe what you will do when it happens so you can practice your quality.

d.) Describe what you will use as a reminder to practice this quality.

e.) Do this for 21 days.

A more frequent parent-teacher conference will play a very vital role in making the plan to create consistency (this, of course will materialize if parents have realized that they have a big part/role on their children's achievement). Peers, parents and school should work together to improve students' performance.

\section{References}

Advokat, Clair. et.al. (2011). "College students with and without ADHD: Comparison of selfreport of medication usage, Study Habits and Academic Achievement." Journal of Attention Disorders, vol.15, n8, p656-666 Nov. 2.

Bugg, Julie M. et.al. (2008). "Improving student's study habits by demonstrating the Mnemonic benefits of semantic processing." Teaching of Psychology, vol.35, n.2, p96-98. 6

Encarta Encyclopedia. 2005

Kim, ChanMin. \& Keller, John M. (2008). "Effects of motivational and volitional email messages (MVEM) with personal messages on undergraduate student's motivation, study habits and achievement." British Journal of Educational Technology, vol.39, n.1, p36-51 Jan. 9.

Kirwan, K. (2006). Developing Good Study Habits.htm. 2006

Mangram, D. (2011) Ten study habits of successful students. In How-to-Study.com.

Ning, H.K. \& Downing, Kevin. (2010). "Connections between learning experience, study behavior and academic performance: A longitudinal study.” Educational Research, vol.52, n.4, p457-468 Dec. 12.

Nonis, Sarath A. \& Hudson, Gail I. (2010). "Performance of college students: Impact of study time and study habits." Journal of Education for Business, vol.85, n.4, p229-238.

Sternberg. (1986). Why Intelligent People Fail. 